\title{
POSIBILIDADES DE UN COMPARATIVISMO INTRA-LATINOAMERICANO (RULFO Y GRACILIANO RAMOS EN LA PERSPECTIVA DE HERMENEGILDO BASTOS)
}

Françoise Perus*

\begin{abstract}
RESUMEN: Con base en las propuestas analíticas del autor de Reliquias de la casa nueva. La narrativa latinoamericana: el eje Graciliano-Rulfo, el artículo considera la pertinencia de replantear las posibilidades de una historia de la narrativa latinoamericana centrada en el estudio y la comparación de poéticas narrativas examinadas en sus contextos históricos concretos. Aun cuando concuerda con el autor en este planteamiento general, discrepa en la concepción de la poética narrativa y el abordaje de la relación entre oralidad y escritura en la poética rulfiana, sugiriendo vías alternas de análisis.
\end{abstract}

PALABRAS CLAVE: Historiografía literaria, Poética narrativa, Oralidad y escritura, Representación histórica, Centro y periferia.

ABSTRACT: Based on the analytical propositions from the author of Reliquias de la casa nueva. La narrativa latinoamericana: el eje Graciliano-Rulfo, the article deals with the pertinence to restate the possibilities of a story of the Latin-American narrative centered on the study and comparison of narrative poetics considered on its concrete historical context. Even coinciding with the author of this proposal on this general statement, disagrees on the conception of the narrative poetics and on the attacking of the relationship between orality and writing in the rulfian poetics, suggesting several alternative ways of analysis.

KEY WORDS: Literatura historiography, Narrative poetics, Orality and writing, Historical representation, Center and surroudings.

En el marco actual de la mercantilización de la cultura, de la reducción del pasado a una dimensión folclórica, y de la disolución de las formas artísticas en la inmediatez de diversas modalidades del performance, la transmisión y recreación del legado de las tradiciones constituye ciertamente un problema acuciante, aunque generalmente pasado por alto. En efecto, la creencia de que un libro "significa" por sí solo, en la "pura"

* Instituto de Investigaciones Sociales, UNAM (perus@correo.unam.mx). 
relación subjetiva con un lector poco o mal formado en las peculiaridades del lenguaje artístico — o mejor dicho de las relaciones, siempre renovadas, que dicho lenguaje entabla, desde su forma propia, con el llamado lenguaje común - , puede sin duda confortar a este lector en la ilusión de la libertad de su propia interpretación. Ésta, sin embargo, suele no ir mucho más allá de un efecto de reconocimiento, que consiste ante todo en reencontrar en el texto lo que se "sabe" de antemano; esto es, en la reproducción de una serie de lugares comunes, de los que cada quien cree ser la fuente más genuina. Con lo cual se pierde de vista el efecto complementario de extrañamiento, más propio de la forma artística que, al desestabilizar la familiaridad aparente del mundo de la ficción, crea de un modo siempre específico y concreto, las condiciones de un auténtico diálogo, a menudo tenso y conflictivo, entre el mundo del texto y el mundo del lector. El fomento a la lectura no se reduce por lo tanto al consumo ampliado de los textos más diversos: culturalmente hablando - esto es, habida cuenta de la dimensión eminentemente reflexiva y autorreflexiva que supone la noción de cultura, al menos en la acepción que de ella nos dejó la "modernidad"-, dicho fomento no puede menos que acompañarse de un esfuerzo concomitante encaminado a la formación artística de los lectores potenciales. Esta formación, que consiste en buena medida en la transmisión de un legado - a la que se abocan en principio maestros, críticos e historiadores de la literatura-, es sin embargo tan problemática como la misma noción de literatura, hoy por cierto bastante maltrecha; no tanto por la falta de "escritores", sino por la renuncia, en aras de la inmediatez dictada por la mercantilización, a todo debate académico serio en torno a la conformación del legado artístico-literario, nacional o no, y a las modalidades conjuntas de su transmisión. Digo renuncia donde, acaso, más valdría hablar de desaliento ante la marginalización de las Humanidades en el seno de las instituciones educativas, y el desplazamiento de éstas por entidades paralelas, primordialmente orientadas hacia lo que se ha dado en llamar las "industrias culturales".

Estas reflexiones de orden general, vienen a cuenta de las que me suscitó la lectura de un ensayo sobre narrativa latinoamericana recien- 
temente publicado por la UNAM, y producto de un intercambio académico con la Universidad de Brasilia. En efecto, no es muy común, hoy en día, encontrar planteamientos de orden historiográfico, que conjuguen el abordaje de los textos literarios desde la perspectiva de su poética histórica y concreta, y desde la de una comparación de autores y obras enmarcados en procesos literarios aparentemente desvinculados entre sí —en este caso el mexicano y el brasileño-. En efecto, en Reliquias de la casa nueva. La narrativa latinoamericana: el eje Graciliano-Rulfo, ${ }^{1}$ el investigador brasileño Hermenegildo Bastos propone acercamientos contrastivos entre Juan Rulfo y Graciliano Ramos, y se vale luego de la relectura de dichos autores para cuestionar algunos planteamientos hoy al uso - y que se remontan en realidad a los años setenta y ochentaen el ámbito de la crítica y la historiografía literarias.

El marco general de interpretación de los textos y los tópicos abordados por Bastos se define, en términos muy generales, como el de la transición de lo "premoderno" a lo "moderno", o de lo "precapitalista" a lo "capitalista"; transición que, para América Latina y sus muy diversas regiones, el autor entiende, siguiendo en esto a Wallerstein, en términos de una "modernización periférica", por referencia al "sistema-mundo" capitalista. ${ }^{2}$ En esta transición, lo propio de la condición "periférica" consistiría en la no homogeneidad del proceso, en las marcadas desigualdades entre regiones y las profundas escisiones socio-culturales que entrañaría este proceso, y por ende en la desarticulación de los espacios y los tiempos de las diferentes culturas dentro de un mismo ámbito nacional (o continental). Las múltiples tensiones que, en el plano de la cultura, resultan de esta transformación desgarradora son las que se expresan en la metáfora que proporciona su título al ensayo de Bastos: mientras el pasado "premoderno", vivo todavía, adquiere la forma de "reliquias", el presente "moderno" se significa con la imagen de la "casa

${ }^{1}$ Hermenegildo Bastos, Reliquias de la casa nueva. La narrativa latinoamericana: el eje Graciliano-Rulfo, México, CCyDEL-UnAM, 2005.

${ }^{2}$ Immanuel Wallerstein, The Modern World-Sistem, Nueva York, Academic Press, 1974. 
nueva". La perspectiva adoptada por el autor consiste por tanto en una visión retrospectiva —o mejor dicho, desde el presente hacia el pasado y viceversa, en cuyo marco los espacios y los tiempos, disímiles entre sí, involucrados en el proceso de transición, se iluminan mutuamente.

Esta misma perspectiva de análisis es también la que organiza la forma de la exposición, en donde no sólo Rulfo aparece antes que Graciliano Ramos, cronológicamente anterior al autor de El Llano en llamas y Pedro Páramo, sino que el estudio de la obra del jalisciense parte de El gallo de oro $(1963)^{3}$ para remontarse luego a Pedro Páramo (1955), antes de concluir con observaciones sobre algunos cuentos de El Llano en llamas (1953). Un movimiento similar puede encontrarse también en las consideraciones del autor acerca de la suerte de la actividad literaria misma, que Bastos llega a calificar también como "reliquia"; esto es, como un "objeto fuera de uso", aunque no por ello desprovisto de "valor estético". Esta visión asaz pesimista acerca de la práctica literaria y creadora acaso pueda entenderse a la luz de las circunstancias presentes, en las que la literatura pareciera haber perdido gran parte de lo que Walter Benjamín llamara su "aura", a raíz del acelerado proceso de mercantilización a la que se halla sometida, junto con otras formas de la creación artística y cultural. ${ }^{4}$ Sin duda harto conflictivas y dolorosas, estas condiciones, sin embargo, no parecen haber sido las que privaban en los años cuarenta y cincuenta, en los que tanto Graciliano, en el Brasil, como Rulfo, en México, bregaban con su propio oficio. Las preocupaciones de uno y otro eran de otra índole, como muestran los mismos análisis que nos brinda el autor de Reliquias de la casa nueva. Pero ¿qué es lo que se habría perdido en el camino, y que Hermenegildo Bastos busca de alguna manera rescatar como "reliquias", a partir de las formas artísticas elaboradas, por separado, por cada uno de estos novelistas?

${ }^{3}$ La fecha indicada es la de su probable elaboración como guión de cine. Su primera publicación, por la editorial mexicana Era, data de 1980.

${ }^{4}$ Véase al respecto, Walter Benjamín, 'L'oeuvre d'art à l'ère de la reproductibilité technique”, Essais 2, 1935-1940, París, Denoël / Gonthier, 1983, pp. 87-126. 
Pese al anuncio de la construcción de un "eje Graciliano-Rulfo", $R e$ liquias de la casa nueva confiere mayor atención a la obra de Rulfo y al análisis concreto de las "poéticas" que rigen las obras del jalisciense. Las consideraciones en torno a Graciliano parten del homenaje y "desagravio" del que, en su momento, fuera objeto el autor de Memoria do carcere, Vidas secas y San Bernardo por parte del gobierno brasileño, y consisten más bien en una prolongación retrospectiva de los hilos entresacados y desenvueltos por Bastos a partir de sus indagaciones acerca de la poética rulfiana. Por ello, voy a centrar mi atención en estas últimas, antes de volver al "eje" trazado y a la discusión que entabla Bastos con las propuestas historiográficas y críticas de los años setenta y ochenta.

Como ya se señaló, el autor emprende la relectura de la narrativa de Rulfo a partir de la menos conocida de sus obras, El gallo de oro, posterior a Pedro Páramo y El Llano en llamas, y generalmente considerada "inferior" a la novela y a los cuentos, acaso por su relación con un proyecto cinematográfico fallido. Según Bastos, El gallo de oro consiste ante todo en la escenificación de las relaciones mercantiles que privan entre los personajes, asociada con las representaciones ilusorias que éstos tienen de estas mismas relaciones. Colocadas bajo el signo de los juegos de azar - las peleas de gallo_-, estas relaciones y representaciones, exacerbadas por el afán de lucro, ponen de manifiesto, y colocan en el centro de la representación artística, una dimensión propiamente política que, a juicio del autor, se hallaría ausente, o que se encontraría menoscabada, tanto en Pedro Páramo como en los cuentos de El Llano en llamas. Y por cuanto el "impedimento" se convierte en el núcleo en torno al cual se organizan las acciones y la caracterización del, o los protagonistas del relato, éste adquiere dimensiones esencialmente trágicas: "Quiero decir — señala Bastos_-, que la tragedia es, primero, la mercantilización de la vida humana y, segundo, el fracaso de las acciones desarrolladas para superar esa condición." 5 Y añade a continuación, después de una discusión con los planteamientos del crítico británico Raymond Williams acerca de la

\footnotetext{
${ }^{5}$ Bastos, op. cit., p. 55.
} 
distinción entre la épica — que ambos vinculan con las luchas sociales y la revolución - y la tragedia — que, como acabamos de ver, Bastos asocia con el fracaso- - "Los acontecimientos narrados en El gallo de oro forman la historia de un doble fracaso, creo yo (dice Bastos): por un lado, el fracaso por no haberse superado el desorden en la construcción de un nuevo orden; por otro, el fracaso del autor en tratar de entender su historia viva." Esta última consideración lo lleva a su vez a la siguiente conclusión: "De esta manera se puede decir que el autor está ahí incluido en la historia como uno de sus personajes, no en la figura de éste o aquel en particular, sino en la figura de su narrador." ${ }^{6}$

En este último punto, algo sorprendente — ¿y acaso destinado a "explicar" el carácter "menor" de este relato de Rulfo?-, el autor se refiere a uno de los rasgos peculiares de los narradores rulfianos, no privativo por cierto de El gallo de oro: a su carácter de "narradores-testigos" que, por encontrarse de algún modo insertos en el mundo narrado, comparten las ambigüedades de éste, y no alcanzan por ello a rebasar la conciencia de los personajes, como, se supone, ocurre en el llamado realismo crítico, definido en su momento por Lukács a partir del realismo europeo. Aun cuando el autor de Reliquias ... no hace referencia explícita a esta tradición del "realismo crítico", y en particular al autor de Significación actual del realismo crítico y Problemas actuales del realismo, ${ }^{7}$ su observación acerca de la forma de los narradores rulfianos descansa sin duda en el contraste entre estos "narradores-testigos" y el narrador "histórico" y en tercera persona que constituía la fuente de la "ironía" - o del distanciamiento - que, según el crítico y teórico húngaro, marcaba la vocación "crítica" del realismo europeo. Sin embargo, la conclusión a la que dicho contraste conduce al autor de Reliquias... no deja de resultar problemática, por cuanto descansa en una supuesta identidad entre el autor (implicado) y la figura del narrador, sea éste un narrador en tercera persona, como en la "narración histórica", o un "narrador-testigo", como en la narración

\section{${ }^{6}$ Ibid., p. 59.}

${ }^{7}$ Georg Lukács, Significación actual del realismo crítico, México, Era, 1963; y Problemas actuales del realismo, México, FCE, 1966. 
rulfiana (y otras más, como veremos más adelante). En efecto, este traslape entre niveles y entes distintos deja sin respuesta tanto el problema de las distintas modalidades de figuración de estos "narradores-testigos" en la composición de las diversas narraciones del jalisciense, como el de la ubicación cognitiva, ética y valorativa del lector (virtual) en y ante el mundo narrado, sugerida desde la poética concreta de la obra de que se trate. El examen de los análisis que, con base en el mismo supuesto, propone Bastos de Pedro Páramo y de algunos de los cuentos de El Llano en llamas, puede contribuir a redondear esta problemática y a vincularla luego con la cuestión historiográfica.

El análisis de Pedro Páramo que propone Bastos coloca a la novela del jalisciense bajo el signo de las "reliquias", no sólo por alusión al planteamiento de Benjamín evocado más arriba, sino por considerar que la problemática se halla planteada de entrada por la metáfora de los "tiliches" — vestigios del pasado - con que se topa Juan Preciado al entrar en la casa de Eduviges Dyada. El autor extiende esta misma metáfora a las voces del subsuelo, que se le aparecen entonces como expresión de la "cosificación" propia de las relaciones sociales modernas. De esta manera, en el plano de la estructura del contenido de la novela, lo "obsoleto" se conjugaría con lo "actual" para poner de manifiesto "la doble temporalidad en que se debe vivir (en América Latina): el tiempo de los países centrales y el tiempo de las colonias." En el marco de esta "doble temporalidad", "reliquias" y "tiliches" - y en particular Susana San Juan en la representación kitch que de ella tiene Pedro Páramo (el personaje) — aparecen como símbolos prestigiosos de "un pasado que no se completa del todo y se mantiene como horizonte enfermizo del presente." ${ }^{8}$ Lo espectral, lo fantasmagórico, alucinatorio u onírico de la percepción que de todo ello tiene Juan Preciado expresarían, a su vez, junto con la disolución de la identidad de éste - como personaje primero, y como narrador después - el hecho de que "haber nacido no es prueba de vivir en el presente."

\footnotetext{
${ }^{8}$ Bastos, op. cit., p. 24.

${ }^{9}$ Ibid., p. 55.
} 
Ahora bien, con base en esta caracterización de la estructura del contenido de la novela, que de paso convierte también a Comala en una "ciudad-ruina", Bastos traslada estas características al plano de la enunciación, para hacer de la novela misma una "ciudad-libro-ruina". Se basa para ello en la identificación de la voz del autor con la de los personajes que, al menos en el caso de Juan Preciado y Dorotea, consisten efectivamente en personajes/voces —o en "narradores-testigos"de características muy disímiles, por cierto- , sin prestar mayor atención, ni examinar con algún detenimiento, la existencia, desde los primeros fragmentos de la novela, de una voz en tercera persona, cuyo estatuto, sin duda extremadamente complejo, resulta sin embargo decisivo dentro de la composición y la arquitectónica novelescas. La reducción de las diversas instancias enunciativas a la voz del autor implicado es, así pues, la que lleva al crítico brasileño a considerar que, por colocarse en el mismo plano de sus narradores-testigos, el autor de la novela queda él también "entilichado"; esto es, preso de aquel mundo de "reliquias" sin otro valor que el halo estético que les confiere la patina del tiempo, y sin saber él bien a bien qué hacer con ellas. La fragmentación y dispersión de la trama, unidas a la ambigüedad como principio básico de organización del sentido, vendrían así a corroborar la serie de impasses (aporías) de las que Rulfo quedó prisionero. Impasses que, según Bastos, atañen en fin de cuentas a la representación de la Historia, y más concretamente a la de los sectores populares y su papel en ella. Cito:

Pedro Páramo es la narración de un problema de representación que, sin ser exclusivamente literario, también es el problema de la representación histórica. La representación de la Historia, la interpretación o comprensión de los acontecimientos vividos por los personajes y por los lectores, parece no estar disponible y, como tal, llega a perderse en un mundo de fantasmagorías. Los acontecimientos narrados se engarzan y sus actores pierden la noción de lo que hacen y de dónde están, se tornan marionetas comandadas por alguna fuerza imperceptible. 
En cuanto la representación histórica se indispone, la literatura alcanza altos niveles de sofisticación. Las dos son vividas como aspectos de un mismo problema que se vuelve, así, un problema de vida o muerte, en la perspectiva de los personajes y de los lectores, así como también del escritor. Y si el asunto es vivir o morir, el problema de la representación literaria es ya, por sí mismo, más que un problema sólo de literatura en el sentido estricto del término. La literatura se coloca, entonces, como algo vital, el acto de escribir como un acto, desesperado tal vez, de lucha por la vida. ${ }^{10}$

Entre las muchas aporías con que tropieza el narrador jalisciense en su lucha por representar la Historia, y más específicamente el lugar y papel de los sectores populares en ella, el investigador brasileño destaca aquel empeño - tantas veces mencionado - del autor de Pedro Páramo y El Llano en llamas, en procurar "escribir como se habla" (y no "hablar como se escribe"). En la narrativa de Rulfo — como en la de otros "transculturados"11_, la relación entre la "oralidad" y la "escritura" constituye sin duda un asunto de primer orden, más de una vez abordado por la crítica. Buena parte de ella se ha limitado a celebrar el fino oído y la destreza estilística del jalisciense; otra ha concebido esta marcada impronta "oral" como "ficcionalización de la oralidad", sin demasiada reflexión acerca de la relación, en extremo compleja, que esta misma impronta guarda con tradiciones literarias varias, escritas y letradas. Respecto del afán de Rulfo por "escribir como se habla", la posición asumida por Bastos es de que no logra su propósito, por cuanto tanto la "oralidad escrita" como la "escritura oral" - términos que toma prestado de los análisis del investigador suizo Martín Lienhard" ${ }^{12}$ — constituyen "ilusiones" de carácter ideológico, que como tales, enmascaran "la contradicción real"; contradicción real que estribaría en el hecho de que, en América Latina, la escritura no ha dejado de ser el privilegio de los sectores dominantes,

${ }^{10}$ Ibid., pp. 76 y 77.

${ }^{11}$ Véase al respecto, Carlos Pacheco, La comarca oral. La ficcionalización de la oralidad cultural en la narrativa latinoamericana contemporánea, Caracas, La Casa de Bello, 1992. 12 "El sustrato arcaico en Pedro Páramo. Quetzalcóatl y Tlaloc", en Claude Fell [coord.], Juan Rulfo. Toda la obra, México, Archivos/Conaculta, 1996, pp. 842-850. 
mientras la "oralidad iletrada" sigue siendo la condición innegable de los sectores dominados. En esta perspectiva, Rulfo se quedaría, así pues, en el "como si", en un papel de "mediador" entre estas dos "culturas":

Lo que aquí existe es una literatura lo más literaria posible. Al contrario de lo que han dicho los teóricos y críticos de la transculturación, los conflictos definidores del hacer literario en América Latina no encontraron aquí una formulación donde la voz popular o subalterna pasan a ocupar el centro. Su posición es, todavía, marginal. ${ }^{13}$

La problemática del lugar, el papel y la voz de los sectores populares en la representación literaria es también, a juicio de Bastos, la que atraviesa la obra de Graciliano Ramos. En ésta, el crítico brasileño no se detiene tanto como en el análisis de la poética rulfiana, acaso por cuanto la obra de Graciliano ya había sido objeto de desvelos críticos anteriores. ${ }^{14}$ Valiéndose en este caso de textos referidos al homenaje y desagravio del que fuera objeto el autor de Vidas secas, Bastos se limita a entresacar los hilos que, en dichos textos, le permiten tejer la madeja —o el "eje"que daría cuenta de tensiones similares en la obra del brasileño y la de su homólogo mexicano. Con todo, las consideraciones del autor de Reliquias... dejan entrever cierta inclinación hacia Graciliano. Por cuanto éste logró, al menos en San Bernardo, hacer que el "iletrado ocupe el lugar de la literatura", ha de considerarse como más "dialéctico" que su homólogo mexicano en la comprensión y representación de la Historia:

En la obra de Graciliano Ramos el silencio del personaje contamina el lenguaje del narrador. Los trazos característicos de Graciliano Ramos - el laconismo y la rudeza del lenguaje - no resultan de una elección estilística pura y simplemente, sino de una ocupación del espacio de la literatura por el iletrado. ${ }^{15}$

${ }^{13}$ Bastos, op. cit., p. 97.

${ }^{14}$ Hermenegildo Bastos, Memorias do cárcere, literatura e testimunho, Brasilia, UNB, 1998.

${ }^{15}$ Bastos, Reliquias..., p. 141. 
Sin duda, las consideraciones de Bastos acerca del narrador brasileño contribuyen a precisar la perspectiva en la que sitúa sus análisis, y las comparaciones que establece entre los dos autores estudiados. Más allá de argumentos o aseveraciones a ratos discutibles como veremos enseguida, el "eje" trazado entre ambos narradores coloca en el centro de la problemática la cuestión de las bases en las que podría descansar la transmisión de tradiciones literarias diversas, a la vez separadas — en este caso, en primer lugar por el idioma-, y sin embargo afines entre sí. Las historiografías literarias nacionales, de cuño historicista o positivista, que privaron en nuestros medios hasta mediados del siglo pasado — hasta que las relegaran las concepciones formalistas y deshistorizadoras traídas por el estructuralismo - no constituyen obviamente sino una de las posibilidades de organización y transmisión de las tradiciones literarias. Pese a sus limitaciones, tanto conceptuales como ideológicos, esta forma historiográfica cumplió mal que bien con brindar "catálogos" de autores y obras que, antes que apuntar a la constitución de un "canon" —en el sentido que el crítico norteamericano Harold Bloom confiere a esta noción ${ }^{16}$ - , pretendían rescatar acervos, configurar tradiciones, y sentar bases para la transmisión, más o menos generalizada, de un legado histórico que formara parte de una cultura nacional y compartida. Sin ella, los debates que surgieron en los años setenta en torno a las modalidades de lectura de las obras y de selección, organización y transmisión de este legado literario, nacional o no, ciertamente no habrían podido llevarse a cabo. Como tampoco podría plantearse hoy la reapertura de estos debates, en un contexto sin duda bastante distinto: el del desdibujo de las fronteras entre textos "literarios" y "no literarios", aparejado con la disolución de la tradición letrada en un "todo cultural", eminentemente a-histórico y mercantil.

${ }^{16}$ Harold Bloom, El canon occidental. La escuela y los libros de todas las épocas, Barcelona, Anagrama, 1995. 
Como corolario de sus planteamientos anteriores acerca de las poéticas narrativas de Rulfo y Graciliano, el último capítulo del libro de Bastos, intitulado "Historia literaria entre acumulación y residuo: el eje Graciliano-Rulfo", tiene - como el libro en su conjunto- varios méritos. En primer lugar, el de restablecer el puente, otrora fructífero, entre teóricos y críticos del Brasil y sus homólogos de la América hispana. Y luego, el de haber centrado sus reflexiones en torno a la forma artística como tal, entendida no en el sentido "formalista" de la palabra, sino como forma viva y concreción de su particular relación con los conflictos históricos, culturales y literarios propios del contexto de su elaboración. En este sentido, contribuye a reubicar la problemática de la lectura y los agrupamientos historiográficos más allá de temas y estilos (de época o de autor), con miras a la construcción de "ejes" que, como las propuestas de los críticos con los cuales discute, sentaran las bases de una organización más comprensiva y explicativa —ni lineal, ni homogénea- de los procesos literarios latinoamericanos.

Respecto de los debates de los años setenta y ochenta, Bastos recoge los planteamientos de Antonio Candido y Ángel Rama, para cuestionar el "superregionalismo" del primero y la "transculturación" del segundo, en tanto esfuerzos por "universalizar la región":

Las lecturas de Candido y Rama tienen un fundamento común: la percepción de la literatura latinoamericana como una zona de conflicto entre lo local y lo universal. La obra de Rulfo, junto con la de Guimaraes y otros, ha sido vista como una especie de coronamiento de un largo proceso de depuración y maduración, por intermedio del cual las culturas locales habrían llegado a marcar una nueva presencia, en la literatura - ya no como registro de la incultura, en general expresado por el personaje iletrado, sino como productora de sentido. ${ }^{17}$

A juicio del crítico brasileño, esta supuesta universalización debe ser reconsiderada a la luz de la "doble temporalidad" que define la forma

${ }^{17}$ Bastos, Reliquias..., p. 131. 
de pertenencia de las sociedades latinoamericanas al "sistema-mundo capitalista", formulada desde tiempos atrás de muy diversas maneras: como oposición entre lo local y lo universal, entre lo arcaico y lo moderno, el atraso y el progreso, la periferia y el centro. Antes que una distribución de los diversos espacios-tiempos sobre un mismo eje temporal progresivo - lo que dejaría suponer que los más rezagados podrían en algún momento alcanzar a los más adelantados-, la doble temporalidad supone la coexistencia conflictiva de estos espacios-tiempos dispares; o dicho de otra manera, que los dos polos de las oposiciones señaladas se "producen" mutuamente. En este marco, y por cuanto la "universalización del regionalismo" no se plantea tan sólo como la elaboración de la coexistencia conflictiva de dichos polos en el espacio-tiempo latinoamericano, sino también y a la par como su superación o su cancelación, dicha "universalización" deja suponer que, al menos en el plano literario, las temporalidades múltiples o las heterogeneidades socio-culturales pudieran constituir "aspectos ventajosos", y convertir así el "atraso" o la "condición periférica" en lo que el mismo Candido llegó a formular como "conciencia amena del atraso". Conciencia amena que, por lo demás y a juicio de Bastos, no sería ajena a buena parte de los estudios "culturales", "poscoloniales" e incluso "subalternos".

Ahora bien, si de evolución o de "avances" se trata, para el crítico brasileño, la problemática tiene que ser reformulada con base en otras preguntas; en particular, en la de ir averiguando hasta dónde los "avances" en el plano literario - manifiestos en una marcada sofisticación formal, aparejada con la incorporación de la voz popular, la puesta en duda de la idea de representación y el auto-cuestionamiento de la literatura - se acompañan de un "avance" similar en el plano de las luchas populares, de la participación de éstas en la Historia y en las formas de representación de la misma. Aun cuando Bastos deja la pregunta sin respuesta, muchas de sus observaciones dejan entrever que ésta sería negativa. Parece incluso sugerir que los reveses de los movimientos populares en las últimas décadas son los que han contribuido a hacer que lo regional y lo popular-oral puedan aparecer como "reliquias", truncando así el 
proceso de "acumulación" que, no sin muchas dificultades, se venía gestando con la incorporación de la voz popular en la literatura y la representación de la Historia. En este punto, Bastos vuelve sobre una polémica encubierta entre Ángel Rama y Antonio Cornejo Polar, ${ }^{18}$ que oponía el énfasis puesto por el primero en la necesidad de la ruptura a la insistencia del segundo en el papel de la tradición y en la urgencia de irla reconfigurando con base en la recuperación de perspectivas de análisis históricas y concretas. Aun cuando, frente a dicha discrepancia, Bastos afirma querer recuperar la "dialéctica" manifiesta en el actual momento de transición, la comparación que establece entre las "reliquias" de Rulfo y la "ocupación de la literatura por la voz iletrada" en Graciliano deja traslucir no sólo su anhelo de ruptura, sino también su concepción de la misma. Acaso las tesis de Rama — sistematizadas unos pocos años más tarde en La ciudad letrada ${ }^{19}$ y según las cuales la historia de la literatura latinoamericana no sería sino la de la segregación del espacio y la institución literarios por parte de sectores "letrados" nacidos con la Colonia y perpetuados en la República—-, sean las que impulsan las reflexiones del autor en esta dirección. Y acaso sea también el actual movimiento de retorno de nuevas formas de dominación oligárquica y transnacionalizada — que parecieran haber echado por tierra la acumulación de fuerzas de los movimientos populares de los años sesenta y setenta - el que pugna de alguna manera en los planteamientos de Bastos, y el que podría ayudar a entender parte de sus dudas y sus zigzagueos. Como sea, si "avances" hubieran en el plano literario, para el autor de Reliquias... éstos no pasarían de la conciencia de sus propios límites que pareciera haber adquirido la literatura latinoamericana.

\footnotetext{
${ }^{18}$ Se refiere concretamente a la entrevista que Beatriz Sarlo hiciera a ambos en 1980: "La literatura de América Latina. Unidad y conflicto", Punto de vista, núm. 8, 1980. Esta edición prácticamente sólo reproduce in extenso la entrevista a Ángel Rama. De una manera general, las diferencias de fondo entre las propuestas analíticas de Rama y Cornejo, y sus implicaciones respectivas, aún quedan por estudiar.

19 Ángel Rama, La ciudad letrada, Hanover, Ediciones del Norte, 1984.
} 
El libro de Hermenegildo Bastos es sin duda inquietante y polémico, lo que no es poco mérito en medios académicos generalmente renuentes al debate. Sus planteamientos y su argumentación son más ricos y matizados de lo que esta apretada síntesis puede transmitir, pero aun así son por los menos dos las líneas argumentativas con las que me gustaría entablar un diálogo abierto. La primera atañe a la concepción de la tradición letrada que Bastos parece compartir con Rama. Ante la acelerada mercantilización a la que, hoy más que nunca, se halla sometida la creación literaria —o más bien sus productos-, considero que dicha tradición no puede desestimarse, ni reducirse a un supuesto papel de legitimación de los sectores dominantes, nacionales o no: nunca, ni siquiera en la época colonial, la práctica literaria se ha limitado a semejante papel, como tampoco es cierto que la llamada literatura universal - la de los países "centrales" u "occidentales" - no haya hecho sino contribuir a la reproducción de la dominación -interna o externa, colonial o neo-colonial- - Y por lo demás, tampoco pienso que el porvenir de la literatura, o de lo que entendemos como tal - con todo y sus contradicciones, o sus complejidades históricas - dependa de que los sectores "iletrados" tomen por asalto la institución literaria. Pienso más bien que ésta, y la tradición letrada, tendrían que ponerse al alcance de todos, mediante un sistema educativo realmente generalizado y amplio, en donde las Humanidades —y la formación artística en particularpudieran recobrar su papel primordial en la educación para la vida, para la vida creativa y socialmente compartida. De ello depende, junto con los modos en que vayamos transmitiendo y recreando el legado de las diversas tradiciones y sus relaciones mutuas, el que la misma noción de literatura, y las prácticas ligadas a ella, se vayan transformando, de nueva cuenta, de cara al porvenir. El problema es político, sin duda, pero es también ... "literario"; o pasa, si se quiere, por una "política de la lectura", puesto que todo escritor es ante todo lector, y lector avezado. En esta dirección, pienso que de la polémica encubierta entre Rama y Cornejo, a la que Bastos alude de pasada sin profundizar en ella, hay mucho más que rescatar. 
La segunda línea de la argumentación de Bastos que me parece discutible concierne a su concepción de la poética narrativa (y de la poética histórica), al menos tal y como la pone a prueba en sus análisis de las obras de Rulfo. Las extrapolaciones que opera el crítico brasileño entre los "narradores-testigos", el autor (implicado) y el lector (virtual) me parecen apresuradas y no lo suficiente atentas a la complejidad de las formas de composición y arquitectónica ideadas por el narrador jalisciense. Al menos a mi entender, estas formas — que son en fin de cuentas las que definen la poética rulfiana - conllevan una transformación de las tradiciones narrativas "letradas" hasta entonces al uso mediante la subordinación de éstas a formas narrativas provenientes de la tradición popular oral. En los acercamientos de Bastos a la poética rulfiana me parece advertir cierta dificultad en desprenderse de los postulados del "realismo crítico" - del que sin duda se deslinda el jalisciense_-, además de una proyección — manifiesta en la tesis de las "reliquias" — algo forzada de las tesis de Adorno. Ambas improntas en la argumentación de Bastos son, a mi modo de ver, las que lo llevan a reiterar en la visión trágica y pesimista de Rulfo, y a pasar por alto formas de humor — io de malicia! - de cuño popular, muy distintas por cierto de la "ironía" propia del realismo europeo. La no comprensión —o no percepción-, por parte de la crítica, de la inversión de la relación de predominio, en la narrativa rulfiana, entre tradiciones narrativas "letradas", por un lado, y tradiciones narrativas orales y populares, por el otro, parte a mi juicio de presuposiciones de orden muy general y ligadas a concepciones de la lengua y el lenguaje, que tuercen o equivocan la ubicación cognitiva, ética y valorativa del lector en y ante las formas de la ficción artística. Esta tergiversación del lugar y papel del lector, en la teoría y en la práctica, es a mi juicio la que ha contribuido a oscurecer las relaciones extremadamente complejas, y siempre renovadas, entre los lenguajes y las formas literarias - escritas - , por un lado, y los lenguajes y las formas "vivas" - habladas - , que privan en los intercambios verbales y sociales concretos - "populares" o no-, por el otro lado. 
La discusión de estos problemas, relativos en fin de cuenta a las formas históricas, sociales y culturales de la enunciación y su relación con la voz ajena, rebasa obviamente el marco de esta exposición. Sin embargo, la vinculación de la narrativa de Rulfo con otras tradiciones más propiamente americanas - la de las Crónicas del Descubrimiento y la Conquista de las que el jalisciense era un lector asiduo, por un lado, y la de los cuenteros pueblerinos, por el otro - acaso contribuirían a entender mejor tanto la peculiaridad de los diversos narradores rulfianos - y en particular la de este "narrador-testigo"-, como su lugar y papel en la composición y la arquitectónica de los cuentos y la novela. Si, en cualquier narración, la voz narrativa - y en las obras de Rulfo suelen ser variasha de entenderse como una convención cultural antes que como una mera función lógica, una de las principales dificultades que, por contraste con buena parte de la tradición europea, plantea la narrativa latinoamericana, radica precisamente en las complejidades de la construcción de esta voz. Y ello por cuanto ella participa por fuerza, y desde los mismos orígenes de la narrativa del subcontinente, de por lo menos dos tradiciones, a la vez separadas y entremezcladas: la de las narraciones orales, y la de las tradiciones escritas y letras, americanas o no. Sin duda, el restablecimiento de esta filiación, y el análisis sistemático de sus muchas complejidades, podría contribuir a aquel "comparativismo contrastivo" -intra- y extra-latinoamericano — planteado hace más de veinte años por Ana Pizarro ${ }^{20}$ — sin que se hayan concretado entretanto los grandes proyectos anunciados-, y retomado ahora por Hermenegildo Bastos. Este nuevo "eje”, y los análisis sistemáticos que plantea, podrían ser también, creo yo, una de la vías que ayudaran a sacar la literatura latinoamericana de su supuesta condición "periférica".

Recibido: agosto de 2006 Aceptado: octubre de 2006

${ }^{20}$ Ana Pizarro [coord.], Hacia una historia de la literatura latinoamericana, México, El Colegio de México/Universidad Simón Bolívar, 1987. Véase en particular, la "Introducción”, pp. 9-20, y el cap. II dedicado a "La perspectiva comparatista”, pp. 33-76. 
